\title{
Simulation of Land Use Evolution by Discrete Events Method: Application to "la Chaîne des Puys" from XV to XVIII Century
}

\author{
Y. MICHELIN ${ }^{\mathrm{a}, *}$ and C. POIX ${ }^{\mathrm{b}}$ \\ ${ }^{\mathrm{a}}$ Dept. Agriculture et Espace \& CNRS UPRESA 6042, ${ }^{\mathrm{b}}$ Dept. Sciences de l'Ingénieur, \\ ENITAC, F63370 Lempdes, France
}

(Received 22 February 1998)

\begin{abstract}
By using a discrete event method, simulation of land use evolution has been applied to a landscape model of "la Chaîne des Puys" (French Massif Central) during a long period (XV XVIII centuries). The indications concerning the evolution of land use are in conformity with the observation of actual situations but the dynamic changes are faster than in actual facts. In spite of limitations due to necessary simplifications, it is now established that the discrete event method is efficient to simulate land use evolution during a long period. The model is immediately able to describe actual dynamics and to show sensitive variables with their critical values. Although oversimplified, it shows how far factors such as level of crops production and taxation can influence land use and landscape changes with a more or less lengthy period. In the future, the model should be bettered by introducing other determined and/or stochastic events.
\end{abstract}

Keywords: Landscape, Simulation, Discrete events, Land use evolution, Rural history

\section{O INTRODUCTION}

Landscape evolution is not a new phenomenon and for centuries, people have been afraid of its dynamics. In France, at the end of the XVI century, Ronsard (1584) deplored forest destruction and landscape damaging. Nowadays, in Europe, there is an increasing social demand for landscape management, especially in order to develop "green tourism" but also to maintain open areas around villages in empty mountains and to fight against forest fires in mediterranean zones. Before proposing efficient management systems, we have to understand why and how landscape evolves.

\section{GENERAL PROBLEM}

Anyone wanting to influence landscape dynamics meets the same difficulties.

\footnotetext{
* Corresponding author.
} 
First of all, we can never be sure that propositions are efficient before they are carried out to their ultimate consequences. Because of long latency periods for answers, when bad results appear, changes are no longer possible. As we wanted to test new methods for predicting landscape evolution, we decided to apply them on historic data in order to compare our predictions with what really occurred during this time.

Secondly, landscape is such a complex concept that it was not realistic to work with real units. We decided to define a simplified model of landscape shapes on which we overlaid the land use at different times to obtain a drawing of landscape. After this first approach, the model has been used as a support for landscape prediction.

Third, the connections between landscape changes and economic, social and ecological factors that produce them are very difficult to clarify. That is why we used a systemic approach on the same area which crossed ecological conditions with management systems, dominated by economic, social and political rules. The results of computerised simulations based on the working rules of the territorial system at that time have been compared to effective landscape reconstitutions obtained by considering various studies: palynology, detailed surveys of plots, analysis of historical documents and archives ... Michelin et al. (1996).

We chose to work on the landscape evolution in the "Chaîne des Puys", because of the abundance of historical and geographical data and studies. The starting point of the study was fixed at the beginning of the XV century (end of the hundredyear war in this region). At that time, the population had almost disappeared and the squires were trying to attract new inhabitants to cultivate their lands. Just as what happened in numerous areas of the "Massif Central" throughout the period of the "Old Regime", the "Chaîne des Puys" was subjected to a method of agro-pastoral management which led to a slow deforestation of the common land and to a conversion of grass land into ploughed land. With the passing of centuries, human pressure increased, forests disappeared almost completely and steep slopes, cleared one by one, were subjected to erosion. Historians Charbonnier (1980) and Poitrineau (1965) explain this phenomenon by an increase in tax pressure (payable with grains) over systems of production unable to increase their yields. We used, directly, archival texts (ecclesiastic series, old administration reports, trials, cadasters). For the oldest period (XV-XVI centuries) we had to use historical studies published by Charbonnier, because the original documents were often either not in contemporary French or badly written with various abbreviations.

To go farther into this idea, we are trying to grade variables and to evaluate thresholds beyond which some socio-economic parameters may influence the occupation of the land. We must point out that we are not interested in historical results for themselves but for their capacity to ratify our hypothesis. Our main aim is to improve a new way of analysing interactions between human activity and land use evolution. The ultimate purpose is to predict effective landscape evolution and to test possibilities of action to redirect this evolution in a way required by the inhabitants or their elected representatives.

\section{MODELISATION METHODOLOGY}

\subsection{Landscape Modelisation and Spatial Discretisation}

Our first approach was to analyse landscape organisation. We based our work on an accurate study of the landscape evolution of the western plateau of the Dômes (Michelin, 1995). We considered that landscape could be described as a set of simple geomorphological shapes on which plots with their land use, buildings, and roads were overlaid. This method enables us to sum up the landscape of "la Chaîne des Puys" in a 3D drawing which is an explanatory model of landscape organisation.

This model deals with four main elements:

- a granitic plateau, with sandy soils, easy to be ploughed, given to crops production; 
- volcanoes and lava flows which overlapped this plateau on its east side, covered with forest in the beginning of $\mathrm{XV}$ century and submitted to clearance throughout the studied period;

- a river valley in the west end of the plateau with dry slopes more or less steep and a wet and flat bottom. The valley was devoted to grass production. In some periods the valley and slopes could be ploughed;

- plateau and river valley are shared in private plots, volcanoes and flow lava are common lands.

For each of these four elements, the lowest level of organisation is the plot. Areas of private plots are small ( 0.3 ha on average), common plots are very large (about $100 \mathrm{ha}$ ). We transformed the 3D model into a very simple $2 \mathrm{D}$ map by using only a quarter of the data. That gave us the rules to discretise geographic space (Fig. 1).

We took advantage of the fact that there is plenty of data on the village of Bravant (Olby). When data was missing, we used other data coming from geomorphological equivalent areas in the west plateau of "la Chaîne des Puys". In our model, the village is located on the plateau. The agricultural soil covers an area of about 80 ha, common lands are twice larger. The agricultural plots have been reduced to a $16 \times 16$ grid. Each square represents a plot of 0.3 ha (an area that could be ploughed in one day). In a first approximation, we assumed that the size does not change in the course of time. Common plots were not shared, but as each peasant was entitled to rights proportional to the number of animals he could feed during the winter, we admitted that each right of use was similar to a part of a plot. So we have represented the common land by a $10 \times 10$ grid. Each element of 0.6 ha area is equivalent to the grazing of a private plot. At the starting time of our study (beginning of the XV century), we decided that the main part of the plateau was ploughed, slopes grazed and the bottom of the valley occupied by meadows $(1 / 3)$ and grass land $(2 / 3)$. Common lands were entirely covered by woods.

\subsection{Socio-economic Aspects of the Model}

Even if some plots were not used, this whole area was managed by peasants and their squire. It represents an economic sphere which can be split into three levels:

- the village, dominated by squire laws;

- the farms with their family (adults + children), the animals (ewes and sometimes cows), hay and crop reserves;

- the plots which constitute the lowest level of organisation.

From the XV to the XVIII century, the exchanges (trade, taxes, purchase, sale,...) are often in kind. Rye is often used and we considered that it was a local currency. With this approximation, we do not have to simulate money fluctuations.

We created a fictitious village and considered that our village has been occupied simultaneously by 16 families who received the same kind of farm (3.8 ha, 10 ewes). Each family was composed of two adults with or without children (random draw). We assumed that the eldest of the family became the rightful heir (no parcelling out, no sharing), that the other children left the farm at the age of 14. In the absence of an inheritor, the liberated plot could be recovered by other lease-holders or reassigned to a new farmer. Historians assume that an adult needed $500 \mathrm{~kg}$ of rye per year for food stuff and $100 \mathrm{~kg}$ for various purchases (clothes, tools, ...). Each peasant ran a private space granted by the squire. The worked plots were subjected to taxes paid in kind. There were three levels of taxes: two were proportional (ecclesiastic "dîme": $1 / 13$ of rye and hay harvest; squire taxes "percière": $1 / 6$ of rye and hay harvest) and one was fixed (king taxes "taille").

\subsection{Agro-ecological Rules}

The plateau was devoted to crops, the steep slopes to grazing land, the bottom of the valley to hay making and to grazing. The top of the slopes, grazing lands at the beginning could easily be cultivated without any problem. On the contrary, 


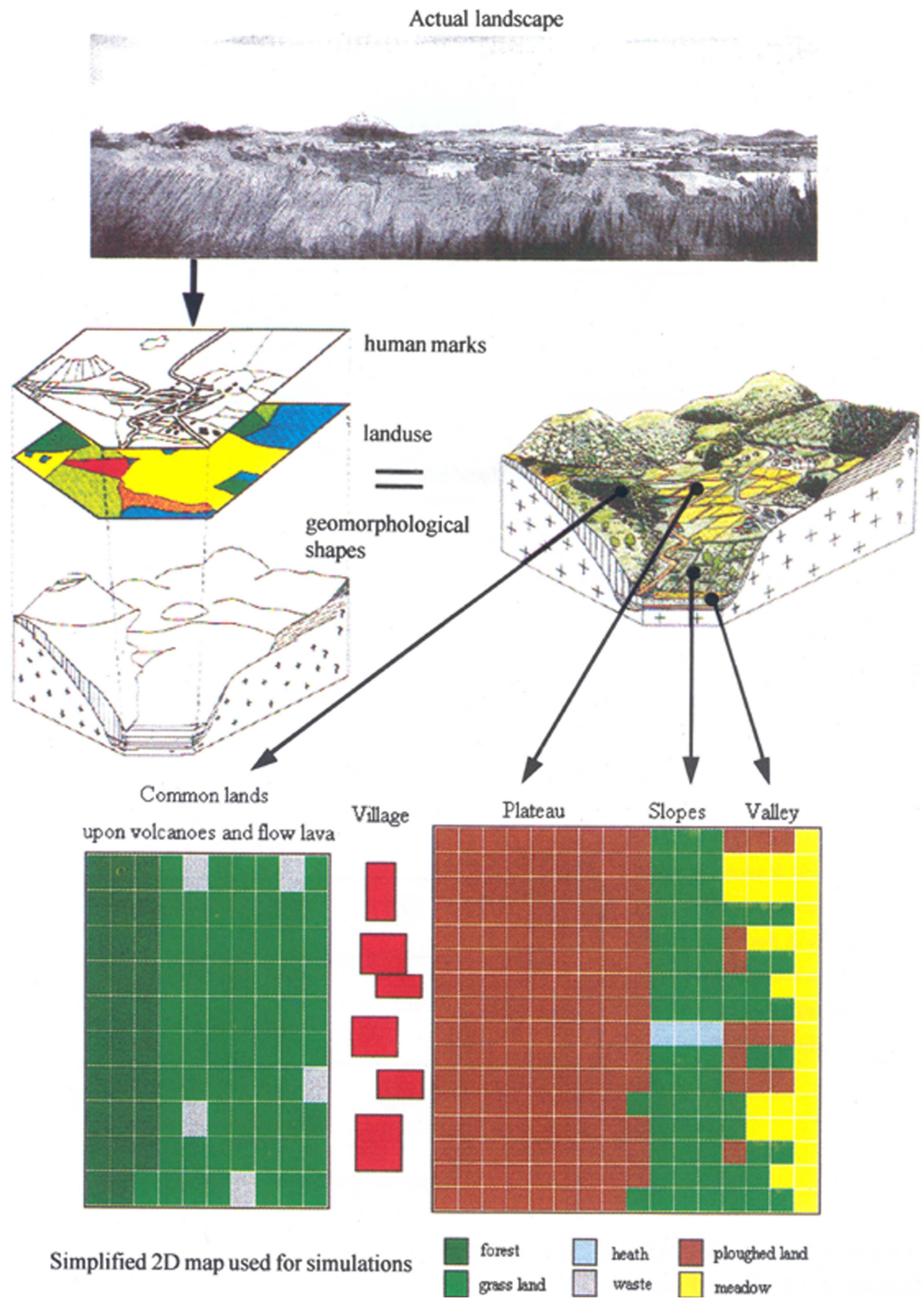

FIGURE 1 Landscape modelisations. (See Colour Plate I.) 
the steep slopes, sensitive to erosion, could only produce for one year if they were cultivated. Then they turned into unproductive heaths. Cereal production (mainly rye) occurred every two years. Land fertility was regained by penning up common flock of sheep on the fallow land every six years in proportion to the number of sheep owned by each peasant (Loiseau and Merle, 1983). When the land to be cultivated was small, the digging was done by using a spade. On larger farms, swing ploughs pulled by cows were used for the tilling. A common space, free from any feudal right was entirely woodland at the beginning. Villagers were allowed to cut wood and graze animals. Pastures could be transformed into ploughed plots or into meadows according to need. The transformation of grazing land could only take place if there was some forest or waste ground left on the common land. A maximum charging capacity has been fixed for common and private lands. We did not include forest production. We assumed that forests could be cleared and transformed into pasture. If this pasture was not used, it became wasteland and returned to woodland after 12 years.

The main element of agro-ecological systems is fertility management. As historians think, we assumed that levels of production did not evolve during the period of the study. By using their data, we consider that the first time a plot was cultivated, its level of fertility was maximum and its production could be the "potential of production". Without any fertiliser, these historians noticed that a second harvest was possible the following year but only with half the production. After two harvests, ten years were necessary to restore fertility. Agronomists showed that the only way known to reduce this time was to manure with the common flock once every six years.

So it was necessary to simulate fertility evolution and its consequences on rye production. That is why we defined an index, the level of fertility, which indicates what a ploughed plot is able to produce.

According to these data, the real production is defined by multiplying the level of fertility by the potential of production, considered as a constant value. The level of fertility changes with regard to what occurred on the plot. Before the first harvest, this level equals one. One harvest means a decrease of $50 \%$. On the contrary, one year fallow or with flock manure increases this level.

\subsection{Definitions of the Variables}

Variables are to be found in three distinct data structures:

- plots (private and common): each plot is defined by its belonging to a geographic unit (plateau, slope, bottom, common land), the nature of its cultivation (meadow, pasture, ploughed land, heath, forest, waste), its level of fertility (between 0 and 1 according to manuring by the flock of sheep), its state (fallow, cultivation, manuring by sheep), its place in the rotation (from 1 to 12 ) and finally by the farmer who runs it.

- the farm: characterised by the number of people involved in it (adults and children), the age of each member, the number of sheep and heads of horned cattle, stocks of grain and hay;

- the village: characterised by the amount of various taxes and potentialities of production, according to the nature of the cultivation.

For rye cultivation, we fixed potentials of production at $380 \mathrm{~kg} / 0.3$ ha (averaged value of the production mentioned by Charbonnier, 1980). For grasslands, we considered that meadows produced $1800 \mathrm{~kg}$ of hay $/ 0.3 \mathrm{ha}$ and pasture could accept a maximum of three ewes per $0.3 \mathrm{ha}$.

\section{SIMULATIONS}

\subsection{Choice of a Method}

Up to now, we described many rules that we use. In this paragraph we discuss how to manage the rules and the variables to perform forecasting.

First of all, we need to choose a method of modelisation to produce a computational model. 
The obtained model necessarily gathers all the aspects presented before (landscape spatial data, socio-economic practices, agro-ecological rules, evolution of the population, etc.).

Most of the available knowledge is of the type "cause $\rightarrow$ consequence". That is why we rejected the purely stochastic method of modelisation. As much as possible, we try to build a deterministic model. In the course of our study, we wrote several formulae describing various precise aspects of the system, for example: tax calculation, variation of fertility of each plot, etc. We understood that an analytical modelisation of the whole system is a mistake for four reasons:

- when we try to link together "micro-systems" dealing with different disciplines, the analytical writing of the final system becomes an awfully complicated formula, which is totally unserviceable;

- the inter-locking of time scales is difficult to handle with this method;

- a lot of rules, just like "the farmer's decision considering the economic state of his farm" are difficult to write with a formula formalism, because it deals with tests and choices rather than calculations;

- an analytical modelisation is not suitable to manage spatial data.

For all these reasons, we decided to use the method called "modelisation by simulation" (Erard and Deguénon, 1996). We are interested in the behaviour of our system. Analytical components are of secondary importance and are not always available. That is why we use discrete technique of simulation. The method consisting of managing a calendar of causal events (each event performs an action on the state variables) is called the "discrete events method". It allows one to work with different scales of time, because there is no fixed step in the time slicing. Each event can be considered as a "micro-model". The events are linked together via their actions on the state variables. They are located in time owing to the calendar management.
As soon as an action becomes complex, it can be split into several simpler events, and graded in time. Even if our model is made up of knowledge coming from various disciplines, we must not forget our aim, i.e. the study of land use evolution. It implies the use of numerous spatial data. According to Coquillard and Hill (1997) "Among all the methods, only discrete simulations allows to really take into account the spatial aspects".

\subsection{Main Events}

\section{(a) General Principles}

The landscape changes discernible down to local patches of soil, are conditioned by the way of managing plots and by the local pedo-climatic context. At the origin of these evolutions, two types of modifications coexist: discrete events (death of the cultivator, surrender of a plot, conversion of a meadow into a ploughed field, frost,...) and continuous evolutions (climatic cooling down, fall of fertility of plots not manured,...). However, these continuous changes may easily be summed over time, if their evolution laws are known. That is why we have submitted the plots and the farms to a series of discrete events, repetitious or unique, aleatory or predetermined. As examples, a nonexhaustive list of events follows:

- stochastic events: births, deaths, infant death rate...;

- determined events occurring each year: payment of taxes, provisions for seeds, feeding of animals and people, buying and selling lands and livestock...;

- causally determined events: war, plague, climatic bad season....

Stochastic causal events will be dealt with in a second stage.

Figure 2 presents a scheme of global calendar of regular annual events: One cycle represents one year. On this scheme we tried to gather events into six groups. The detailed composition of each rectangle is shown in Table I. 
The events are sorted out and numbered in chronological order within a year. Some of them modify plot parameters (fertility update, rotations, erosion, ...), some concern farm variables (animal feeding, births, deaths, ...), some express the consequence of a decision of a farmer upon a plot (conversion of a pasture to a meadow or a ploughed plot after a lack of production, clearance of a part of the common wood,...).

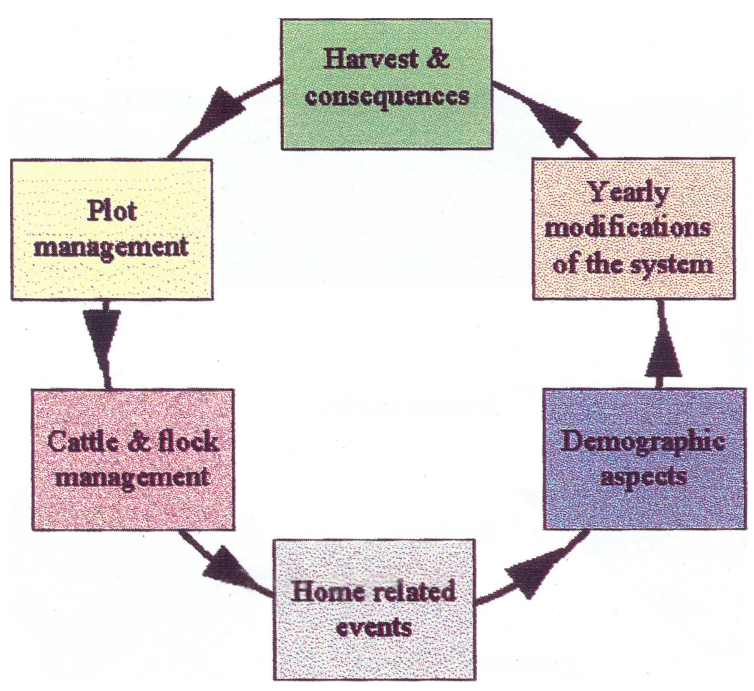

FIGURE 2 Calendar of regular annual events. (See Colour Plate II.)
In order to clarify our model, we made a classification of the events. There are numerous possible classifications; the one presented in Fig. 3 is based on the actions performed by the events on different kinds of variables. We distinguish four sub-models that partially overlap: Population, Cattle \& flock, Stocks and Plots. The polygonal zones shown in Fig. 3 represent these sub-models.

Each event appears as a numbered circle. The meanings of the numbers are presented in Table I. The position of each circle indicates what kind of variable is modified when a given event occurs. For example: (4)(erosion) modifies only variables related to plots. On the contrary, (23)(buying plots and cattle) modifies three kinds of variables: plots, cattle and stocks (goods are paid in grain).

Although this figure looks quite complicated, it allows one to understand how the sub-models that seem independent can modify each other, thanks to the events. For example, a birth (19) directly acts on the population. To avoid children's starvation (14) a new mouth must be fed (13), therefore a birth indirectly acts on the stocks. A decreasing of stocks may involve the ploughing of a pasture (22) to produce more cereals (1); the new ploughed land must be manured (11), etc. So we can see that an event, minor though it may be, indirectly affects the whole state of the model.

TABLE I List of the main events

\begin{tabular}{ll}
\hline Harvest \& consequences & \multicolumn{2}{l}{ Plot management } \\
$\mathbf{( 1 )}$ Harvest & $\mathbf{( 4 )}$ Erosion \\
$\mathbf{( 2 )}$ Tax payment & $\mathbf{( 5 )}$ Fertility update \\
$\mathbf{( 3 )}$ Decapitalization & $\mathbf{( 6 )}$ Rotation \\
& $\mathbf{( 7 )}$ Ssowing \\
Cattle \& flock management & Home related events \\
$\mathbf{( 8 )}$ Feeding of animals & $\mathbf{( 1 3 )}$ Food reserve for people \\
$\mathbf{( 9 )}$ Animals/hay ratio adjustment & $\mathbf{( 1 4 )}$ Children starvation \\
$\mathbf{( 1 0 )}$ Selling of animals & $\mathbf{( 1 5 )}$ Rural depopulation \\
$\mathbf{( 1 1 )}$ Flock manuring & $\mathbf{( 1 6 )}$ Various purchases \\
$\mathbf{( 1 2 )}$ Flock reproduction & \\
Demographic aspects & Yearly modifications \\
$\mathbf{( 1 7 )}$ Increase of ages & $\mathbf{( 2 2 )}$ Ploughing of pastures \\
$\mathbf{( 1 8 )}$ Children departure & $\mathbf{( 2 3 )}$ Purchases of plots and cattle \\
$\mathbf{( 1 9 )}$ Birth & $\mathbf{( 2 4 )}$ Meadow to pasture conversion \\
$\mathbf{( 2 0 )}$ Children mortality & $\mathbf{( 2 5 )}$ Purchase of ewes \\
$\mathbf{( 2 1 )}$ Death/inheritance & $\mathbf{( 2 6 )}$ Management of heirless properties \\
\hline
\end{tabular}




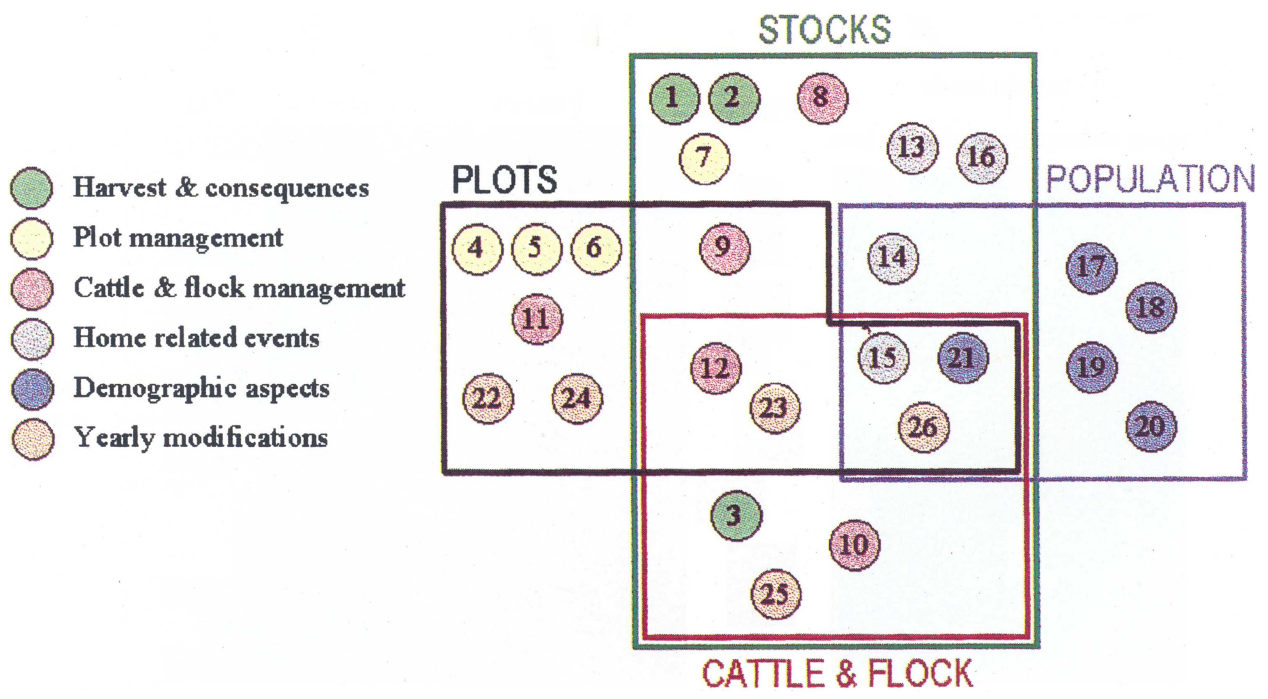

FIGURE 3 Classification of main events. (See Colour Plate III.)

The more complete the event list is, the more realistic the model is. Fortunately, the events are very easy to define because we just have to care for the direct actions. The indirect modifications are handled by the simulator.

The MAGE software (Poix, 1997) is based on the methods of simulation by discrete events. It works on PC/Windows (minimum configuration: PC386, VGA color Adaptor).

The simulator manages a calendar of events sorted out in chronological order. A library of events permits the user to modify the model without having to modify the program. Each event corresponds to an independent subroutine which will operate on the state variables of the system. The organisation in modules allows the programmer to enrich the library without modifying the code core of the simulator. An automatic backup enables working in sessions. It also permits to keep track of the simulated events plot by plot and farm by farm. All the results can be transferred to a spreadsheet or any data analysis software for further study. Finally, the initialisation file and the backups of state variables are written in a very simple format. The user can rapidly modify the initialisation of the model with a text editor.
To explain how events have been translated into computer language, we present an example of each in the following parts.

\section{(b) Example of Events that Affect only Plots}

Rotations The variable "rotation" is a pluriannual calendar (from 1 to 12 ) that indicates what occurs in each plot: when the number is odd the plot is seeded, when the number is 2 or 8 the plot is fallow and can be manured by the flock of ewes (the duration of the penning on the fallow land being proportionate to the number of sheep owned by the farmer), for the other even numbers, the plot is left fallow.

Erosion On the plateau, when farmers ploughed steep slopes, it was impossible to maintain a production more than one year. Historians noticed that this problem of erosion increased in the end of the XVIII century. So, in our model, each plot situated on steep slopes is examined each "year" and transformed into unproductive heath if it had been ploughed the year before.

Reforestation Ecological studies (Michelin, 1988) demonstrate that cleared common lands which have not been grazed for some time (ten 
years minimum) will turn again into a forest. These pieces of information are stored into two variables: land use (grassland if grazed, fallow if not grazed for less than ten years, wood after ten years without any grazing) and age of desertion ( $=0$ if land use is wood or grassland, from 1 to 10 in the other case). Each year, if a fallow plot remains deserted, age of desertion increases from 1 till this value reaches 10 . Then, land use is changed into wood and age of desertion becomes 0 .

\section{(c) An Example of Events that Concern only Farm Variables: Buying a Cow}

At the end of one "year", when taxes have been paid, fields sown, animals and inhabitants fed, farmers may buy animals if they have enough grain to pay. A cow is worth $200 \mathrm{~kg}$ of rye. We assumed that this value did not change because when cows cost more in some periods, at the same time, the price of cereals increased with approximately the same coefficient. Even if this quantity of grain was available, it was not sufficient to allow farmers to buy. They had to check that they had enough hay to feed the new animals in winter. Historians Charbonnier (1980) and Poitrineau (1965) indicate that a cow ate $1800 \mathrm{~kg}$ of hay a year. Each "year", the program examines the level of stocks for each farmer. Only those who have more than $200 \mathrm{~kg}$ of rye and the capability of keeping $1800 \mathrm{~kg}$ of hay at the end of winter were allowed to buy a cow and all of them would do it.

\section{(d) Events which Change Variables of Plots after Farmer's Decision: Change of Land Use}

Different events allow a change of land use when the statement of supply (hay, cereals) is negative. For instance, if a farmer is short of hay, he can decide to transform a pasture into a meadow. If a farmer needs more cereals to feed people or to pay more taxes, he has the possibility of ploughing a plot which was grazed but some conditions have to be respected. A grazed plot is ploughed when the stock of grain is negative and if it is possible to clear a part of the common forest to offset the decrease of pasture area. Priority of change is given to plots which stay at the end of the plateau (sandy soils, no slope). The plots lying at the bottom of the valley come in second position. The slopes are ploughed last, because of erosion.

An event is activated only if specific variables match defined values. For instance, reforestation needs a value of ten for the variable "age of desertion" and fallow for the variable "land use". For buying a cow, the variables "stock hay" and "stock grain" must be respectively equal to or greater than 1800 and $200 \mathrm{~kg}$.

\subsection{First Results}

We carried out simulations of long periods covering several decades, even several centuries to test the model stability. We then compared the results with the actual situation of the village (total number of inhabitants, global size of the livestock, land use). We carried out statistical survey in order to determine reliability of obtained results. Finally, we studied the sensitivity of some parameters such as taxes, demography and management method of livestock.

The simulator produces three kinds of data:

- maps of land use at different times (Fig. 4);

- curves of evolution of some global variables (population, afforestation rate, number of ewes and cows) (Fig. 5(a) and (b));

- global database that gathers the values of all the variables for each "year".

We ran the simulator in order to forecast land use evolution during 150 "years". We replicated the simulation 50 times to have an idea of the variability.

The results provided by the first simulations show that the model is stable. The indications concerning the evolution in the land use are in conformity with the observation of actual situations (progressive disappearance of the forest, progression of the ploughed space, huge variability of population along the time but very stable in the 

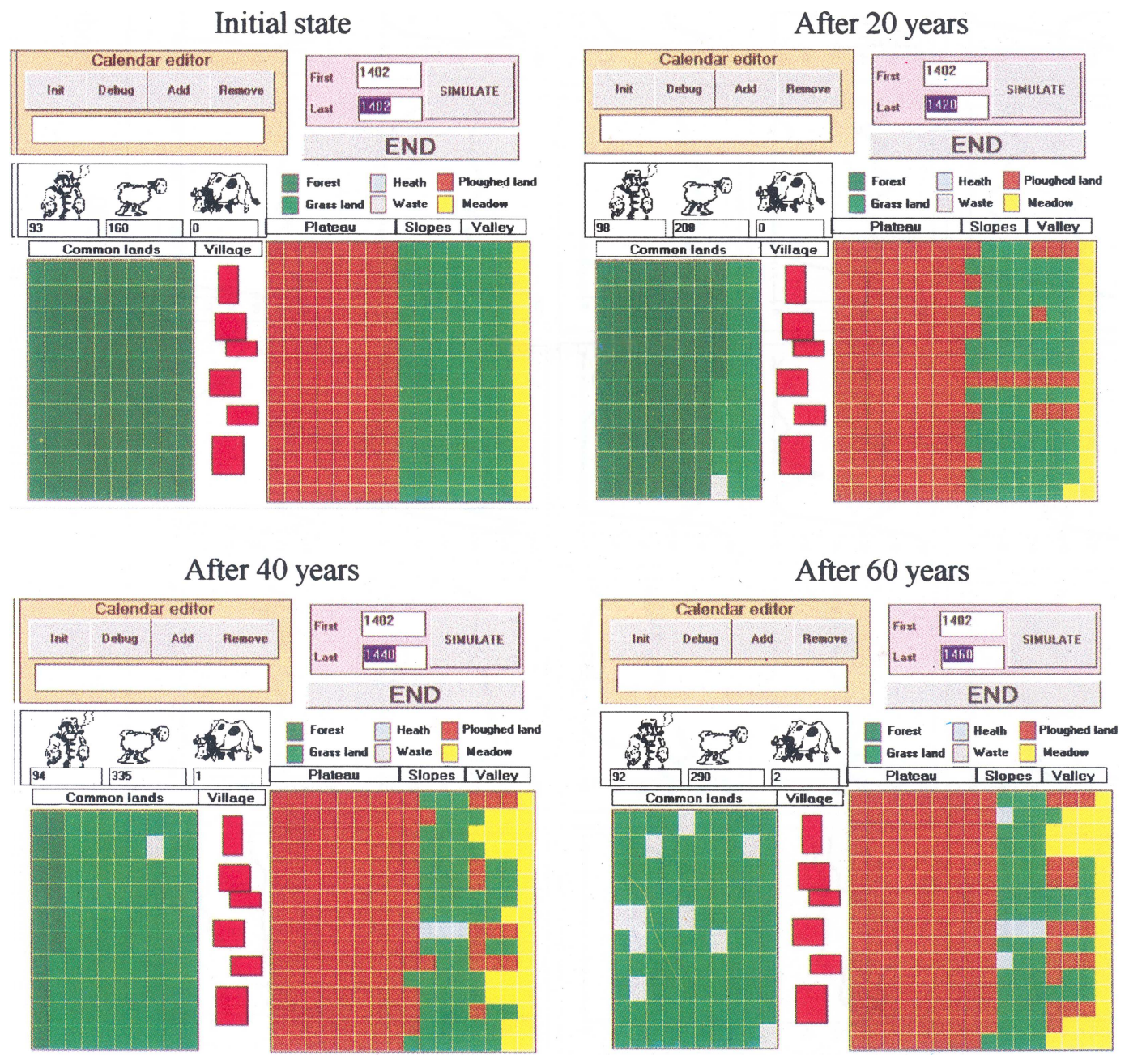

FIGURE 4 Simulated maps of land use at different times. (See Colour Plate IV.)

long term). We noticed that the dynamic movement is faster than it is in reality.

The model already enables one to point out very sensitive variables such as fiscality or level of cereal production. We decided to run the simulator over a period of 150 years, with six levels of production (from 100 to $600 \mathrm{~kg} \mathrm{rye} / 0.3 \mathrm{ha}$ ) and five levels of taxes $(0,50,100,150,200 \%$ of actual level $)$ and we compared the curves of afforestation rate and population (Fig. 6).

Thus, we distinguished three kinds of dynamics:

- if taxes are high and production low, clearance in the forest is not very important but population decreases;
- on the contrary, if taxes are low and production high, population increases but forests disappear quickly;

- between these extreme situations, population and forest are more fluctuant.

This example shows that in this kind of very autarcic economy, levels of taxes and production are able to influence land use dynamics in the long term. This is a demonstration that landscape can be for a part determined by technico-economic conditions.

\subsection{Discussion}

Consequently, we are able to explain why global evolution is similar to the actual, but why it runs 


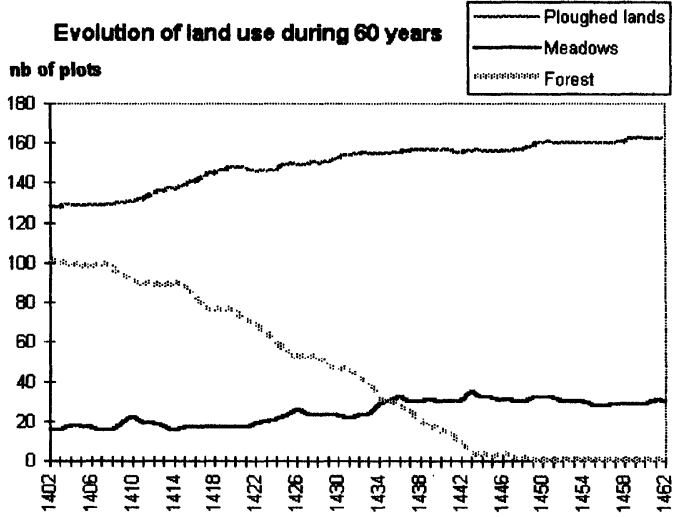

(a)

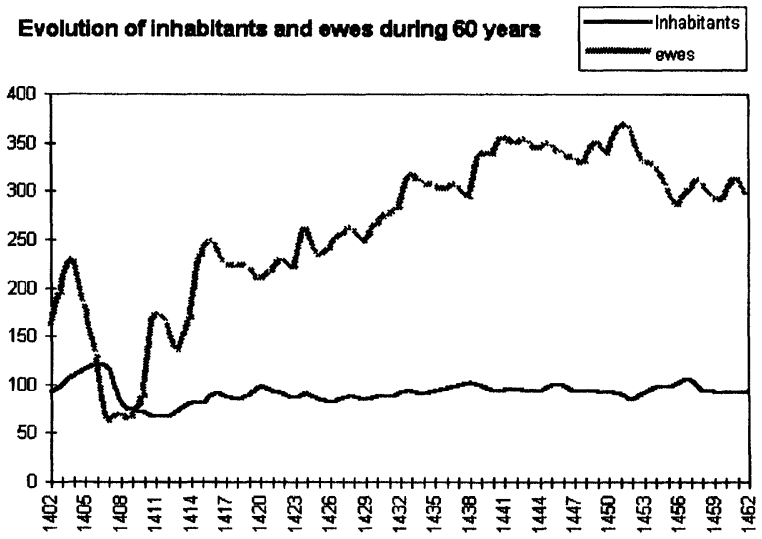

(b)

FIGURE 5 (a) Evolution of land use during 60 years. (b) Evolution of inhabitants and ewes during 60 years.

more quickly:

- firstly, we did not introduce risks of low production (bad weather, diseases of plants or animals, ...) and climatic degradation of short ice age (XVIII century);

- secondly, a few very important determined events (religious war, black plague) have not yet been introduced;

- thirdly, a few socio-economic changes have not been inserted in the model (increase of squire taxes in the XVIII century, competition between inhabitants and squire for common land grazing).

In fact, all these events are very negative for farmers and produce the same kind of effects. They limit population development, so they put a brake on the capability of farmers to better their conditions. If they are less numerous, they need less crops and they have less manpower for clearing and ploughing so they are less active against forests. That is why forest areas decrease more quickly in the model than in reality.

In spite of these limitations, due to necessary simplifications, it is now established that the discrete event method is efficient enough to simulate land use evolution during a long period. Our model is immediately able to describe actual dynamics and to show sensitive variables with their critical values. In the future, it should be bettered by introducing other determined and/or stochastic events (diseases, wars, climatic fluctuation). It is also possible to demonstrate that socio-economic conditions influence landscape evolution with a more or less lengthy period. For instance, in the same period of 150 years, forestation rate could oscillate (actual data of the "Old Regime") instead of decreasing regularly (less taxes and more production as it happened in the XIX century).

Of course, it is advisable to go deeper into this subject, to improve our model. In particular, environmental and agronomical data are still too summary. We considered that all the plots had the same potential and that the latter did not change with time, that of course is not the case.

At last, the model reveals the difficulties linked to the interlocking of time scales. If we want to consider long term dynamics, we must necessarily simplify reality as much as possible and not pay attention to minor changes in short periods which do not invalidate general dynamics. Thus, in order to achieve that, the great evolutionary cycles must already be known, which is not always obvious. For each variable and for each period we should therefore carefully examine the interval of validity of the events that we defined. Thus, for example, we consider that in the absence of an inheritor, the squire reassigned the leasehold to a newcomer. That is admitted for the XV to the XVI century period, but seems less systematic from the second half of the XVII century onward. But these limitations, instead of 
Y. MICHELIN AND C. POIX

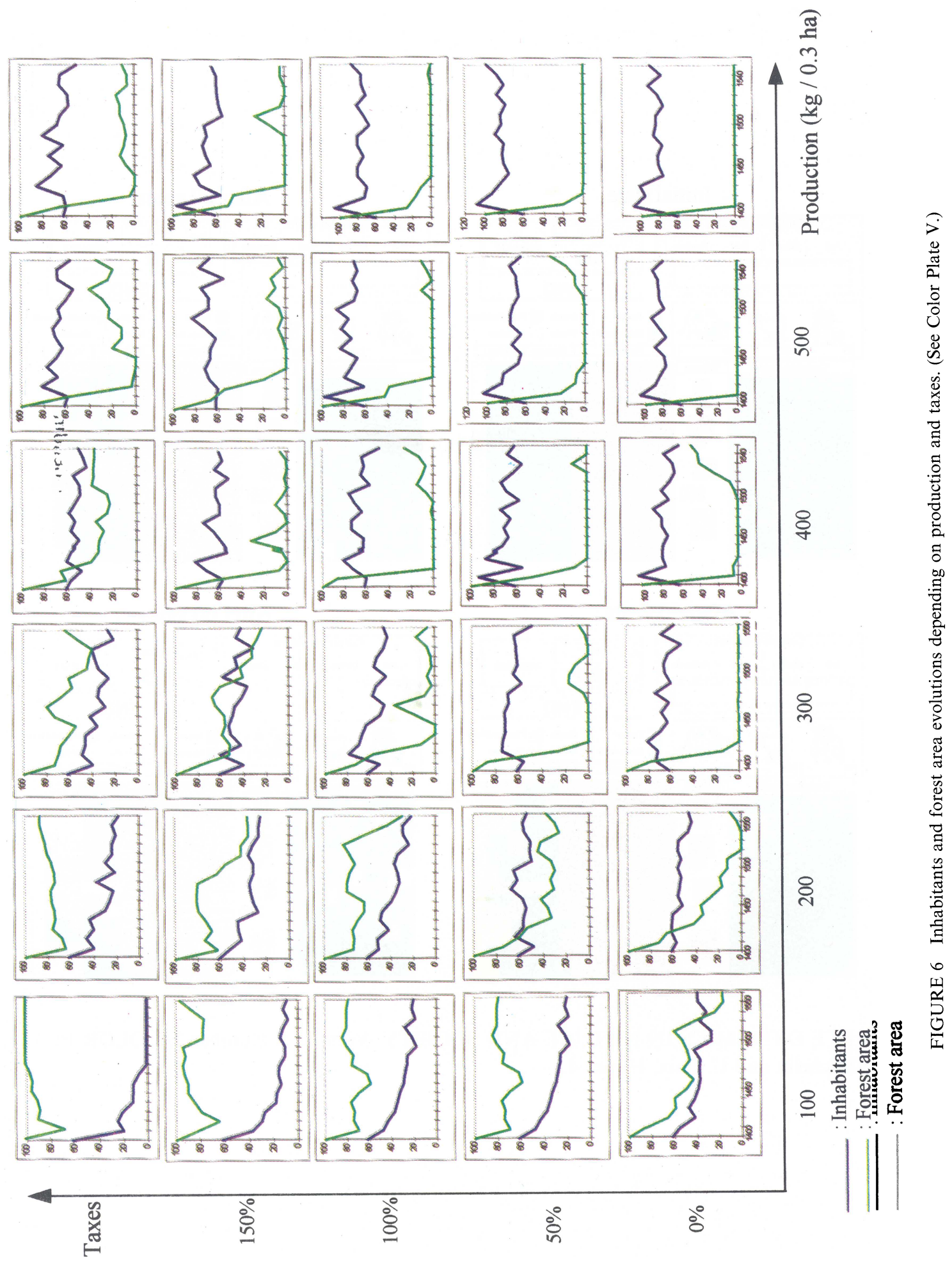


preventing us from concluding, give elements to better our knowledge about interlocking scales of space (plot, farm, village) and time (the year, the agronomic time - rotations, the human time generations, the socio-economic time - "Old Regime" from XV to XVIII century). As this method seems to be promising, we are now thinking of overlaying simulation results with GIS to produce realistic 3D views of landscape (Fig. 7). Such pictures applied to present and future landscapes will be very useful to help people to take decisions dealing with landscape management.
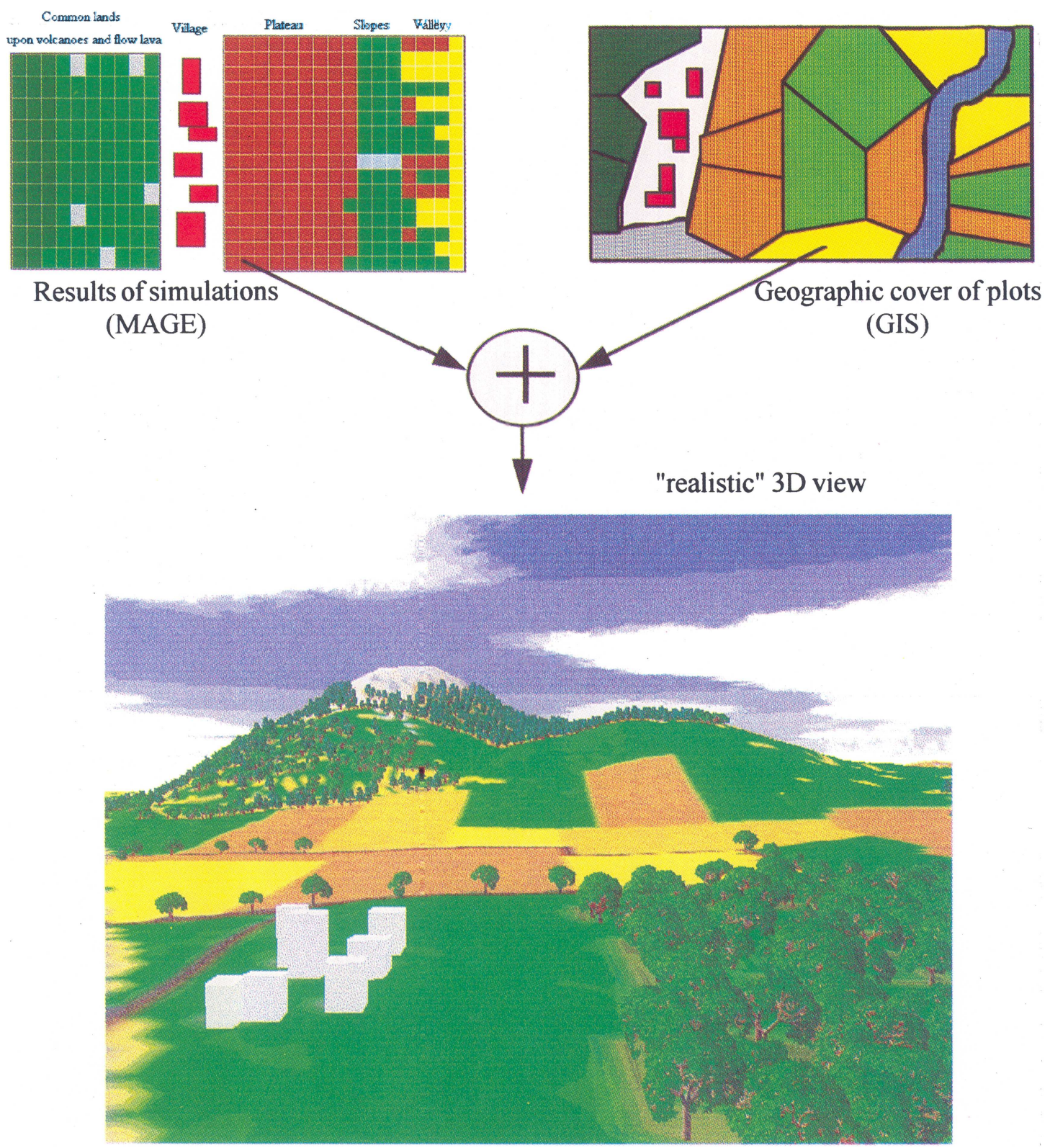

FIGURE 7 3D realistic views of landscapes will be made by using GIS and the results of simulations. (See Colour Plate VI.) 


\section{CONCLUSIONS}

We are quite aware of the present limits of the model presented here. Its ultimate purpose is not to describe reality with accuracy but to progress in the understanding of interactions between socioeconomic factors and environmental context. The first results of a co-operation between agronomist, geographer and computer scientist enable us to conclude already that the simulation by discrete events is quite relevant to our set of problems. Although oversimplified, the present model shows how far factors such as level of crop production and taxation can influence land use and landscape changes. We must now improve it, so that environmental parameters and non-determined events are better integrated. Then the interpretation of results will be more complex and will have to be based on calculation of confidence intervals, multi-spectral analysis of the data obtained from numerous replications.

\section{References}

Charbonnier, P. (1980). Une autre France, la seigneurie rurale en Basse Auvergne du XIVe au XVIIe siècle. Institut d'études du Massif central, Clermont-Ferrand, 1293p.
Coquillard, P. et Hill, D. (1997). Modélisation et Simulation d'Écosystèmes: des Modèles Déterministes aux Simulations par Evénements Discrets. Masson, Paris, 273p.

Erard, P.J. et Deguénon, P. (1996). Simulation par événements discrets: concepts et réalisations en Simula, Ada, et Smalltalk. Presses polytechniques et universitaires romandes, Lausanne, $417 \mathrm{p}$.

Loiseau, P. et Merle, G. (1983). Un puissant outil d'amélioration des parcours, le parcage nocturne. Agronomie 3(4), 375-385.

Michelin, Y. (1988). La végétation et l'évolution des paysages de 1950 à 1982. l'exemple de la chaîne des Puys, Massif central français. DEA Université Blaise Pascal, ClermontFerrand, 42p.

Michelin, Y. (1995). Les jardins de Vulcain: paysages d'hier, d'aujourd'hui et de demain dans la chaîne des puys du Massif central français. Éditions de la MSH, Paris, $155 \mathrm{p}$.

Michelin, Y., Vergne, V., Denèfle, M. et Cohen, J. (1996). Méthodologie pour une reconstitution paysagère: un exemple dans la chaîne des Puys de la fin de l'empire romain au XVIII ème siècle. l'Homme et la Nature au Moyen-Age, Errance, Paris, actes du Vème congrès d'archéologie médiévale, Grenoble, 1993, 57-62.

Poitrineau, A. (1965). La Vie Rurale en Basse Auvergne au XVIIIe Siècle (1726-1789). Presses Universitaires de France, Paris.

Poix, C. (1997). Software MAGE.

Ronsard, P. (1584). Elégies, XXIV. 


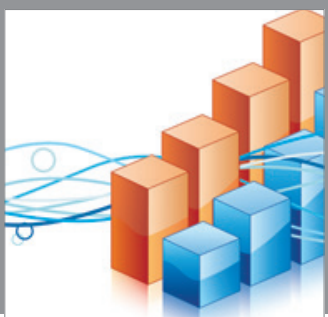

Advances in

Operations Research

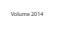

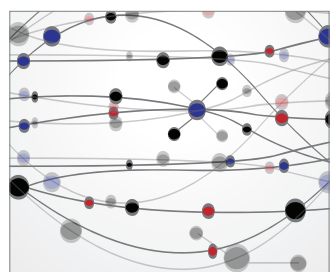

\section{The Scientific} World Journal
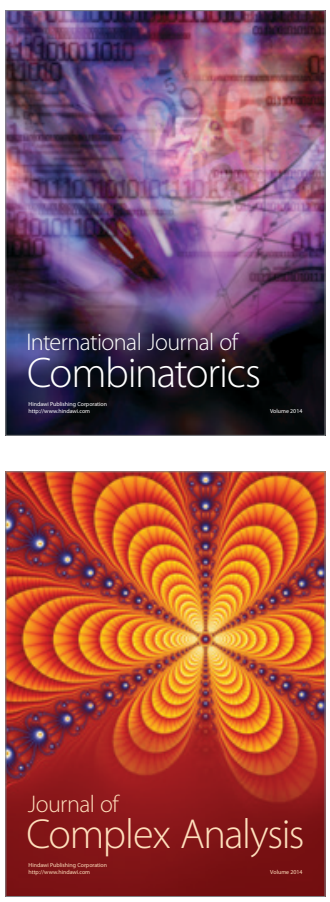

International Journal of

Mathematics and

Mathematical

Sciences
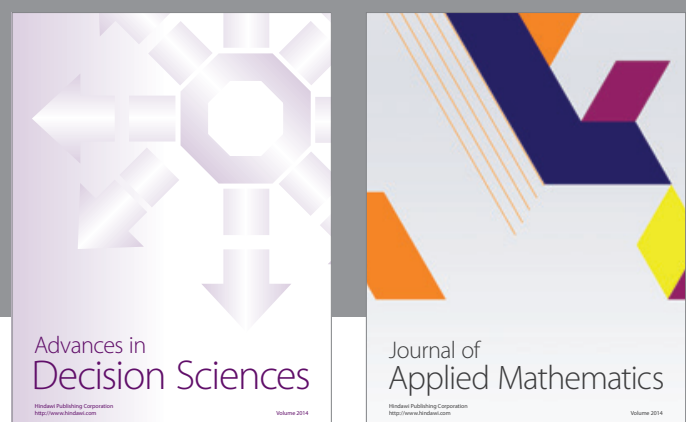

Journal of

Applied Mathematics
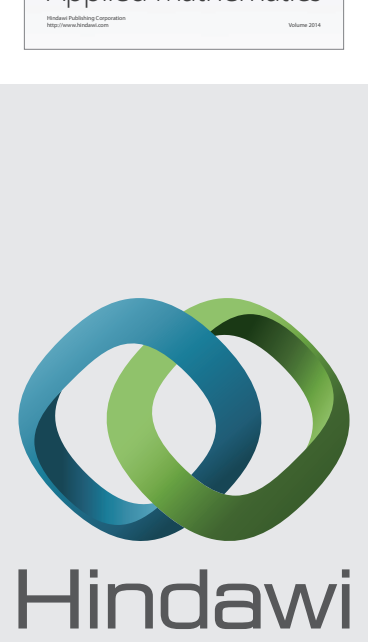

Submit your manuscripts at http://www.hindawi.com
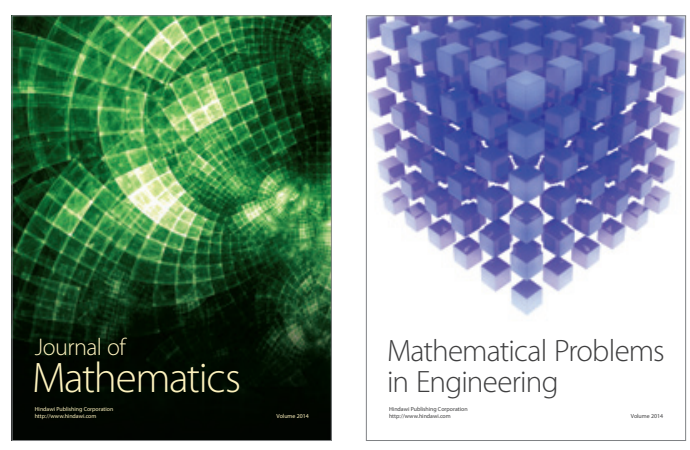

Mathematical Problems in Engineering
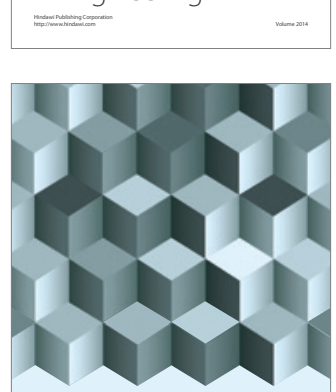

Journal of

Function Spaces
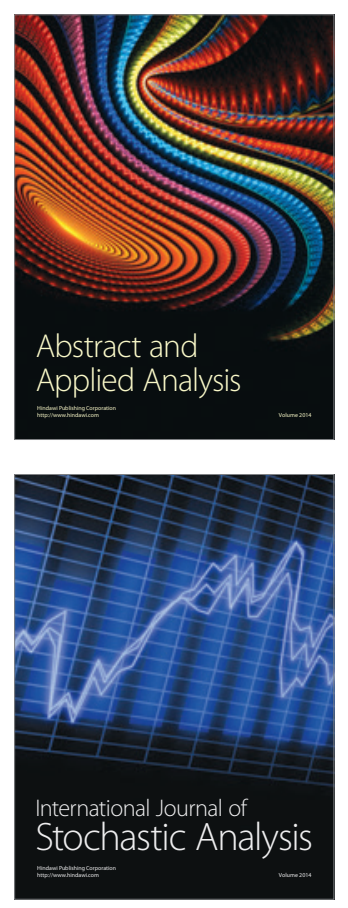

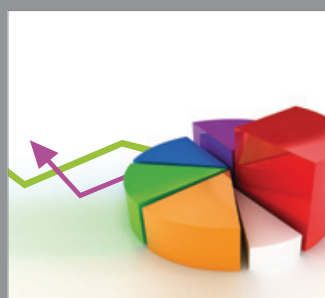

ournal of

Probability and Statistics

Promensencen
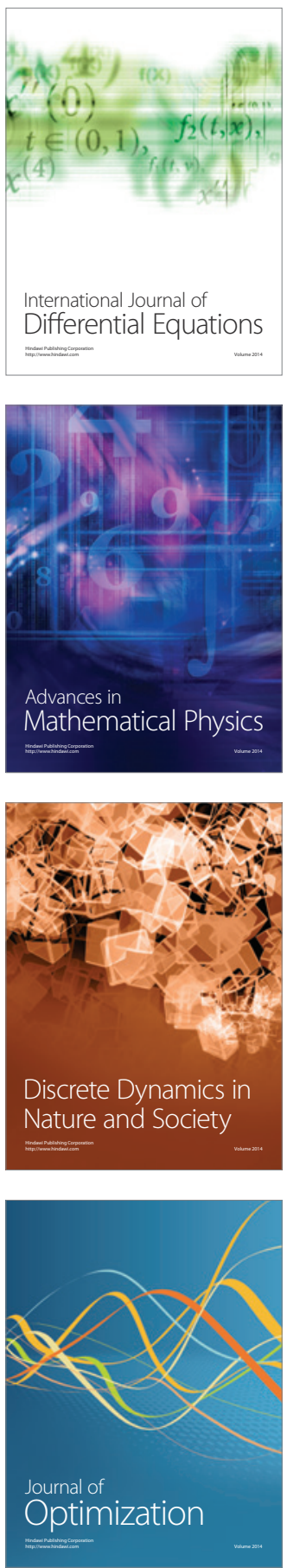